БЕЛОКОНЕВ Сергей Юрьевич - кандидат политических наук, доцент департамента политологии факультета социальных наук и массовых коммуникаций Финансового университета при Правительстве РФ (125993, Россия, г. Москва, ГСП-3, Ленинградский np-кm, 49; SYUBelokonev@ fa.ru)

ШАШЕНКОВ Александр Олегович - аспирант департамента политологии факультета социальных наук и массовых коммуникаций Финансового университета при Правительстве РФ (125993, Россия, г. Москва, ГСП-3, Ленинградский пр-кm, 49; AOShashenkov2019@edu.fa.ru)

\title{
ПОЛИТИЧЕСКИЕ ФАКТОРЫ ИНВЕСТИЦИОННОГО ПРОЦЕССА В РЕСПУБЛИКЕ КРЫМ
}

\begin{abstract}
Аннотация. В статье анализируются политические факторы, влияющие на инвестиционный процесс в Республике Крым. По данным рейтингового агентства «Эксперт РА» и Агентства стратегических инициатив прослеживается динамика рейтинга инвестиционной привлекательности Крыма для российских и иностранных инвесторов. Авторы анализируют эффективность мер государственной поддержки в рамках региональной инвестиционной политики в Республике Крым и определяющую роль деятельности региональных властей в развитии инвестиционного процесса. Авторы приходят к выводу, что специфика складывающегося в Крыму регионального политического режима определяет механизмы и возможности взаимодействия бизнеса и власти, а также специфику экономического развития республики в условиях санкционного давления.

Ключевые слова: инвестиционный процесс, политические факторы, региональный политический режим, региональная инвестиционная политика, взаимодействие власти и бизнеса
\end{abstract}

$\mathrm{O}$ дним из важных условий экономического развития и политической стабильности России является эффективное привлечение финансового и человеческого капитала в регионы страны, и эти задачи обозначены в стратегиях регионального развития в рамках федеральной и региональной экономической политики. При этом привлечение инвестиций в субъекты федерации, выравнивание экономического пространства страны и создание конкурентных условий для инвестирования обозначаются как прямые задачи региональных властей. В рамках настоящего исследования предполагается уточнить группу политических факторов инвестиционного процесса на примере Республики Крым и продемонстрировать их роль в качестве катализатора активности инвесторов.

В исследовании применяются методы вторичной обработки и анализа открытых статистических данных, а также компаративный политико-экономический анализ динамики инвестирования в Республике Крым в период 20152020 гг. На практике трансформации инвестиционного процесса в Крыму за последние годы прослеживается, что характер генерации конкретных мер региональной инвестиционной политики и степень успешности их реализации связаны с особенностями регионального политического режима, который имеет авторитарные черты и базируется на иерархических взаимодействиях с опорой на авторитет и силу регионального лидера.

Привлечение инвестиций - это процесс, имеющий ключевое значение для экономического роста в стране. Комплекс политико-экономических мероприятий, разрабатываемых и реализуемых государственной властью, определяющих конкретные подходы к взаимодействию с бизнесом разного масштаба, созданию для него правовых, экономических, инфраструктурных и 
административно-управленческих привлекательных условий, и составляет инвестиционную политику государства. И.И. Иваницкая, давая определение государственной инвестиционной политики, выделяет ее основные задачи: это создание благоприятной инвестиционной среды; реализация комплекса мероприятий с целью поиска источников инвестиций и определения областей экономики, требующих инвестиционных вложений [Иваницкая 2006]. По мнению Д.В. Куницына, перед региональной властью стоит задача согласования интересов государства, местного самоуправления, бизнеса и населения и создания условий для привлечения инвестиций [Куницын, Куницына 2017].

Определяя группировку политических факторов инвестиционного процесса, мы выделяем несколько направлений.

Первым направлением указанной деятельности является правотворческая деятельность. В рамках правового обеспечения государственной политики поддержки инвестиций в Республике Крым в сжатые сроки был разработан ряд программ, законов и иных нормативных актов, которые существенно упростили деятельность участников инвестиционного процесса. В частности, в республике действуют:

1) закон Республики Крым «О стратегии социально-экономического развития Республики Крым до 2030 года» от 28.12.2016 г. ${ }^{1}$;

2) государственная программа «Социально-экономическое развитие Республики Крым и города Севастополя» ${ }^{2}$, которая включает обеспечивающую подпрограмму и федеральную целевую программу «Социально-экономическое развитие Республики Крым и г. Севастополя до 2022 года»3;

3) федеральный закон «О развитии Республики Крым и города федерального значения Севастополя и свободной экономической зоне на территориях Республики Крым и города федерального значения Севастополя» 4 ;

4) закон Республики Крым от 2 июля 2019 г. № 624-3РК/2019 «Об инвестиционной политике и государственной поддержке инвестиционной деятельности в Республике Крым» и др. [Брега 2020].

Вторым направлением является организационно-управленческая деятельность: проведение выставок, форумов и иных мероприятий для привлечения региональных, федеральных и мировых инвесторов (например, в 2016 г. Ялтинский международный экономический форум позволил привлечь в республику 70 млрд руб. инвестиций); создание и поддержание активности государственных институтов (структур, организаций, ведомств) на федеральном и региональном уровне.

Третьим направлением выступает информационное сопровождение: поддержание новостной повестки, сотрудничество с региональными и федеральными СМИ; размещение открытой информации на сайтах государственных органов;

\footnotetext{
1 Закон Республики Крым «О стратегии социально-экономического развития Республики Крым до 2030 года». Доступ: https://storage.strategy24.ru/files/strategy/201906/2d4be799191ec f70cc188c45d5607cff.pdf (проверено 26.12.2020).

2 Постановление Правительства РФ от 30.01.2019 № 63 «Об утверждении государственной программы Российской Федерации "Социально-экономическое развитие Республики Крым и г. Севастополя”». Доступ: http://static.government.ru/media/files/hL7WAqlAI9CNtX pmHRHqAEipclP4pW20.pdf (проверено 26.12.2020).

3 Постановление Правительства РФ от 24.03.2020 № 328. Доступ: https://programs.gov.ru/ Portal/program/45/passport (проверено 26.12.2020).

4 Федеральный закон от 29.11.2014 № 377-Ф3 «О развитии Крымского федерального округа и свободной экономической зоне на территориях Республики Крым и города федерального значения Севастополя». Доступ: http://kremlin.ru/acts/bank/39100 (проверено 26.12.2020).
} 
активное внедрение цифровых форм управления инвестиционным процессом; формы удаленной работы с инвесторами в период пандемии COVID-19 и др.

Четвертое направление связано с политикой преодоления негативного воздействия на политико-экономическую сферу республики международных санкций. С разной степенью успешности региональным властям удалось в довольно сжатые сроки переориентироваться на устойчивые экономические и политические связи с материковой Россией. Крымские санкции, которые в очередной раз продлены на полгода - до 21 июня 2021 г., - включают ограничительные и запретительные меры экономического воздействия, в т.ч. запрет на импорт крымских товаров, запрет на любые инвестиции стран Евросоюза, в т.ч. в виде технологий. Фактически пресечен туризм из-за запрета входа судам в 7 крымских портов, а самолетам - посадки в аэропортах Крыма и других ограничений ${ }^{1}$. Негативное влияние санкций на ситуацию в Крыму заключается в фактической приостановке работы международных банков и значительных препятствиях в работе российских банков, в проблемах с мобильной связью, сложностях с международным транспортным сообщением, визовом режиме, энергетической блокаде. Эти проблемы достаточно эффективно решались и решаются региональной властью при поддержке федерального центра. В частности, глобальные инвестиционные проекты, такие так строительство Керченского моста, энергомоста, Таврической и Балаклавской ТЭС, газопровода Кубань - Крым, позволили обеспечить энергетическую и транспортную независимость полуострова.

Динамика инвестиционной привлекательности Крыма. Региональное правительство Крыма активно создает условия для инвестирования в регион. В настоящее время действуют специальные структуры во власти, которые созданы с целью стимулирования инвестиционной активности в регионе. Это, например, Совет по улучшению инвестиционного климата Республики Крым, Корпорация развития Республики Крым², Центр инвестиций и регионального развития ${ }^{3}$. Особую роль в стимулировании инвестиционной активности в регионе играет Свободная экономическая зона, которая просуществует до конца 2039 г. ${ }^{4}$

Анализ динамики инвестиционной привлекательности Республики Крым по материалам Рейтингового агентства $R A E X$ был осуществлен по данным экспресс-оценки инвестиционной привлекательности Республики Крым ${ }^{5}$. Подробный мониторинг «Эксперт РА» начинает с 2014 г., используя данные Укрстата и Государственного казначейства Украины, а в дальнейшем Росстата, ЕМИССа, Минфина РФ, Казначейства РФ, Банка России, МВД, Минприроды, Минкомсвязи, данных сайтов отечественных и иностранных рейтинговых агентств. Представляет интерес возможность сопоставления результатов оценки «на входе» и заявленных аналитиками возможностей для Республики Крым с актуальными на сегодняшний день данными, а также выявление степени влияния политических факторов инвестиционного процесса в Республике Крым на позитивные инвестиционные решения.

\footnotetext{
1 Евросоюз продлил на год санкции в отношении России по Крыму. - ТАСС. Доступ: https://tass.ru/mezhdunarodnaya-panorama/8759815 (проверено 26.12.2020).

2 https://kr82.ru/gospodderzhka (проверено 26.12.2020).

3 https://russiaindustrialpark.ru/centr_investiciy_i_regionalnogo_razvitiya (проверено 26.12.2020).

4 Свободная экономическая зона. - Сайт Министерства экономического развития Республики Крым. Доступ: https://minek.rk.gov.ru/ru/structure/609 (проверено 26.12.2020).

5 Экспресс-оценка инвестиционной привлекательности Республики Крым: рискованный актив. - RAEX.Доступ: https://raex-a.ru/researches/regions/krim_2014(проверено 26.12.2020).
} 
Таблииа 1

\section{Показатели Республики Крым в Рейтинге инвестиционной привлекательности} регионов России

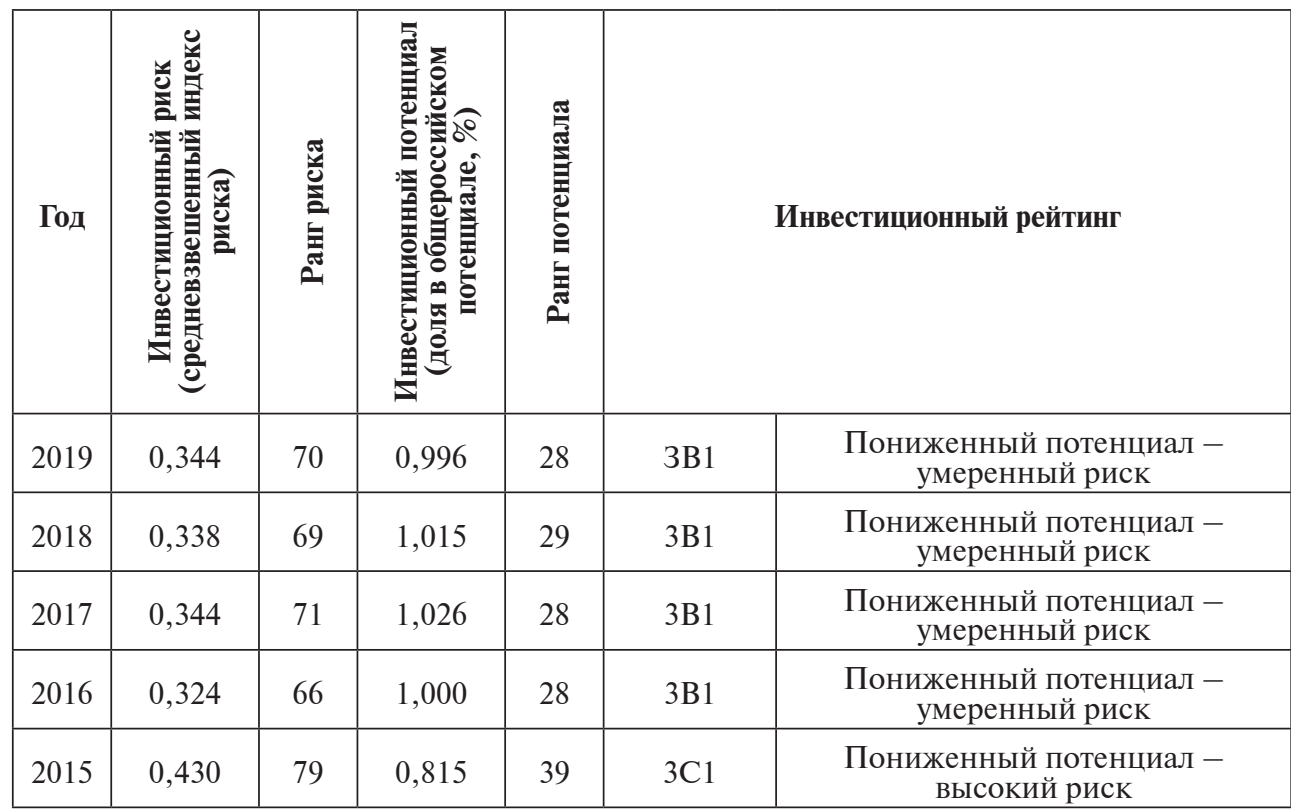

Источник: РА «Эксперт».

* Международный проект «Лучшие практики привлечения инвестиций в регионы». $R A E X$. Доступ: https://raex-a.ru/project/regcongress/2019/resume (проверено 26.12.2020).

Динамика инвестиций также подробно представлена на портале Управления федеральной службы государственной статистики по Республике Крым и г. Севастополю.

Таблииа 2

Основные показатели инвестиционной деятельности в Республике Крым по данным Росстата

\begin{tabular}{|l|c|c|c|c|c|}
\hline & 2014 & 2015 & 2016 & 2017 & 2018 \\
\hline $\begin{array}{l}\text { Инвестиции в основной капитал, } \\
\text { млн руб. }\end{array}$ & 26446,8 & 47582,3 & 74795,3 & 196193,0 & 296423,1 \\
\hline $\begin{array}{l}\text { Индекс физического объема } \\
\text { инвестиций в основной капитал, } \\
\text { в к п предыдущему году }\end{array}$ & $\mathrm{x}$ & 134,3 & 136,3 & 235,7 & 134,3 \\
\hline $\begin{array}{l}\text { Инвестиции в основной капитал } \\
\text { в расчете на 1 жителя, руб. }\end{array}$ & 14034,1 & 25023,5 & 39167,3 & 102560,5 & 154970,2 \\
\hline
\end{tabular}

* Составлено по: https://crimea.gks.ru/storage/mediabank/\%D0\%9F\%D0\%BE\%D0\%B A\%D0\%B0\%D0\%B7\%D0\%98\%D0\%9E\%D0\%9A2014-2018.pdf (проверено 26.12.2020).

Часть инвестиций на региональном уровне осуществляется государством, которое участвует в инвестиционных проектах как прямыми бюджетными финансовыми вложениями, вкладами в основные фонды, так и с помощью 
разветвленной системы госгарантий и льгот (например, льготные кредиты, разница в процентных ставках, по которым бюджет компенсирует затраты кредитной организации). Как видно из данных Росстата, значения показателей инвестиций в республику имеют волнообразный характер. Это связано с эпизодами прямого государственного инвестирования. Так, по последним данным, в общей структуре инвестирования $48 \%$ составляют государственные инвестиции, а $52 \%$ - частные. Крым является особым регионом, в котором только устанавливаются как региональные механизмы взаимодействия местной власти, бизнеса и общества, так и отношения на внешнеполитическом фронте, которые отягощены санкционными мерами.

Поданным Агентства стратегических инициатив и результатам Национального рейтинга состояния инвестиционного климата в субъектах Российской Федерации в 2020 г. Крым занял 43-е место (улучшив позицию по сравнению с 2019 г. на 18 пунктов). Указанный рейтинг включает 44 показателя по 4 направлениям: это регуляторная среда, институты для бизнеса, инфраструктура и ресурсы, поддержка малого предпринимательства. В 2020 г. рейтинг показал рост показателей Крыма по 13 позициям, среди которых можно выделить такие, как «оценка механизма государственно-частного партнерства», «доля компаний, столкнувшихся с давлением со стороны органов власти или естественных монополий», «региональная организация по привлечению инвестиций и работе с инвесторами», «интернет-портал об инвестиционной деятельности», «оценка консультационных и образовательных услуг, оказываемых организациями инфраструктуры поддержки малого предпринимательства в регионе» и «доля государственных и муниципальных контрактов с субъектами малого бизнеса в общей стоимости государственных и муниципальных контрактов»1.

Рассмотренные в данном исследовании политические факторы инвестиционного процесса играют первостепенную роль (хотя и не являются определяющими) в формировании инвестиционной привлекательности Крыма. Характер регионального политического режима предопределяет эффективность реализации инвестиционных проектов, а значит и степень привлекательности для инвесторов.

На наш взгляд, довольно высокие ожидания от инвестиционной привлекательности Крыма, особенно туристической области, отчасти не реализовались в полной мере из-за активного влияния политических факторов. То есть, именно управленческие параметры, на наш взгляд, являются определяющими для специфической ситуации Крыма, где инвестиционный климат выстраивается не эволюционно, а в результате скачкообразных тенденций, обусловленных высокой политической заинтересованностью федерального центра. Регион не поставлен в условия естественной конкуренции с другими субъектами в полной мере, а ожидает предвосхищенные инвестиции (в инфраструктуру, в туризм), которые даже при недостаточно эффективном освоении будут «прощены» региональным властям [Пырма 2020]. Мы определили региональный политический режим в Крыму как централизованный авторитаризм, который сложился, а точнее, складывается в настоящее время под влиянием политико-культурных исторических предпосылок, объективных факторов и субъективного вклада чиновническо-управленческого корпуса в привычные для региона общественно-политические отношения. При этом при максимальных федеральных дотациях в регион объяснимы тенденции к централи-

\footnotetext{
${ }^{1}$ Крым повысил позиции в рейтинге инвестиционного климата. - Крымское информационное агентство. Доступ: https://kianews24.ru/news/krim-povisil-pozicii-v-reytinge-inves/ (проверено 08.01.2021).
} 
зации, вертикальному контролю, назначению ставленников, полностью подконтрольных федеральному центру. Подобная тактика предполагает снижение управленческих рисков для центра, но для самих назначенцев создает сложные задачи по успешному встраиванию в региональную систему общественных отношений, что требует взаимного приятия и взаимодействия (доверие, коммуникация, достижение консенсуса по важнейшим вопросам социально-экономического развития с местными элитами). Конфигурация элитарных интересов по локальной-региональной-федеральной линии демонстрирует пока не преодоленные противоречия, причем особняком стоят потребности местных элит и групп интересов. Губернатор является связующим звеном между местными элитами и федеральным уровнем и главным распорядителем ренты, гарантом субсидий и персонально ответственным за эффективное управление, а также главным контролирующим звеном, определяющим механизмы контроля. В свою очередь, выказывая доверие губернатору, федеральная власть повышает легитимность его полномочий и его статус. Централизованный авторитаризм поддерживается за счет адаптации инициированных федеральным центром программ, при этом в них заложены возможности автономии региональной власти в пределах предмета своего ведения.

Вопросам изучения качества управленческих характеристик региональной и местной современной крымской элиты посвящено не так много работ. Несомненно, это связано с относительно коротким периодом существования региона в составе России, но уже сейчас можно обратиться к некоторым важным наблюдениям ученых. Так, А.А. Кудлай обращает внимание на постепенные перестановки в составе правящей региональной элиты - в Государственном совете Республики Крым, правительстве Республики Крым - с сохранением устоявшихся в регионе (еще в составе Украины) механизмов рекрутирования. Автор приводит такие особенности рекрутинга, как местничество, закрытый характер сообществ, поставляющих новые кадры, необходимость линейного восхождения по карьерным лестницам, связанность с действующим губернатором. Источниками новых кадров служат не только низовые звенья аппарата власти, но и бизнес, силовые структуры, политические партии, различные общественные структуры (например, Общественная палата республики). Указанные тенденции схожи со всеми постсоветскими республиками и, в целом, отражают факт несформированности регионального кадрового резерва. А.А. Кудлай обращает внимание на важные для нашего исследования характеристики новой складывающейся крымской элиты, такие как авторитаризм, безынициативность и ожидание жестких вертикальных приказов от высшего руководства. При этом наблюдается постепенная тенденция изменения стиля управления за счет притока управленческих «варягов» с материка, имеющих опыт эффективного администрирования и призванных в республику как раз с целью налаживания системы государственного управления [Кудлай 2016]. При этом в процессе включения Республики Крым в общенациональную политическую систему, который предопределил усиление роли федеральных и региональных элит при ослаблении местных лидеров, становится очевидной главенствующая связующая фигура губернатора и его команды. Неспособность местных элит к консолидации, обусловленная, среди прочих причин, и традиционным этнополитическим разобщением, выступает и некоторым гарантом невозможности создания значимой оппозиции. Как пишет А.И. Яковлев, толерантность в межкультурной коммуникации в Республике Крым присуща бытовому уровню, а в области политических отношений преобладает этническое лобби и конкуренция различных этнических и иных групп [Яковлев 2018]. 


\section{Список литературы}

Брега А.В. 2020. Политико-правовые аспекты вхождения Крымского полуострова в состав Российской Федерации: между легальностьюи легитимностью. Гуманитарные науки. Вестник Финансового университета. Т. 10. № 1. С. 84-89.

Иваницкая И.И. 2006. Инвестиции и инвестиционная политика. Корпоративное управление и инновационное развитие экономики Севера: Вестник НИЦ корпоративного права, управления и венчурного инвестирования Сыктывкарского государственного университета. № 2. С. 50-66.

Кудлай А.А. 2016. Портрет региональной административно-политической элиты Республики Крым. - Приволжсский научный вестник. № 2(54). С. 175-178.

Куницын Д.В., Куницына Е.М. 2017. Развитие региональной инвестиционной политики в Новосибирской области. - Развитие территорий. № 3(9). C. 39-43.

Пырма Р.В. 2020. Структура сетевых сообществ социальных медиа в информационном потоке внешнего давления на Крым. - Гуманитарные науки. Вестник Финансового университета. № 10(4). С. 65-72.

Яковлев А.Н. 2018. Внешние риски развития социокультурной конфликтности в Крыму. - Геополитика и экогеодинамика регионов. № 4(14). С. 405-414.

BELOKONEV Sergei Yur'evich, Cand.Sci. (Pol.Sci.), Associate Professor of the Department of Political Science, Faculty of Social Sciences and Mass Communications, Financial University under the Government of the Russian Federation (49 Leningradsky Ave, Moscow, GSP-3, Russia, 125993; SYUBelokonev@fa.ru)

SHASHENKOV Aleksandr Olegovich, postgraduate student at the Department of Political Science, Faculty of Social Sciences and Mass Communications, Financial University under the Government of the Russian Federation (49 Leningradsky Ave, GSP-3, Moscow, Russia, 125993; AOShashenkov2019@edu.fa.ru)

\section{POLITICAL FACTORS OF THE INVESTMENT PROCESS IN THE REPUBLIC OF CRIMEA}

\footnotetext{
Abstract. The article analyzes the political factors influencing the investment process in the Republic of Crimea. According to the Rating Agency «Expert RA» and the Agency for Strategic Initiatives, the dynamics of the rating of investment attractiveness of Crimea for Russian and foreign investors is traced. The authors analyze effectiveness of state support measures in the framework of the regional investment policy in the Republic of Crimea and the determining role of the activities of regional authorities in the development of the investment process. The authors conclude that the specificity of the regional political regime emerging in Crimea determines the mechanisms and possibilities of interaction between business and government, as well as the specificity of the republic's economic development under the pressure of sanctions.

Keywords: investment process, political factors, regional political regime, regional investment policy, interaction between government and business
} 